\title{
Study of the Precipitation Behavior and Strengthening of Carbides during the Partition Process
}

\author{
Peiyang JIANG, Fei ZHAO* \\ College of Materials and Metallurgy \\ Guizhou University \\ Guiyang, China \\ e-mail: 131555919181@qq.com, fzhao@gzu.edu.cn
}

\begin{abstract}
In this paper, the size distribution and quantity of carbides precipitated during the partition process of ${ }_{60 S i} \mathrm{CrVA}_{2}$ spring steel treated by Q\&P with different partition time were statistically analyzed by SEM. Carbide particles were obtained by electrolytic extraction of $60 \mathrm{Si}_{2} \mathrm{CrVA}$ treated by Q\&P with partition time of $1200 \mathrm{~s}$, and the contribution of different kinds of carbides to the yield strength was calculated. The results show: during the partition process of $60 \mathrm{Si} 2 \mathrm{CrVA}$ spring steel, the size and volume fraction of carbides increase continuously with the extension of partition time, while the contribution of carbides to yield strength decreases gradually. Carbides rich in $\mathrm{V}(\leq 80 \mathrm{~nm})$ and carbides rich in $\operatorname{Cr}(>80 \mathrm{~nm})$ are mainly precipitated in the partition process, and carbides rich in $V$ play the key role in precipitation strengthening.
\end{abstract}

Keywords-60Si2CrVA spring steel; $Q \& P$ process; Partition time; Carbides; Precipitation strengthening

\section{INTRODUCTION}

Spring steel is widely used in aircraft, railway vehicles, such as automobiles and tractors transport and other industrial products. It mainly work in bending periodic, alternating torsion stress conditions, subjected to pull, pressure, shock, torsional fatigue, corrosion and other effects, sometimes bear high short-term sudden load. So the comprehensive mechanical properties of spring steel high requirements. The microstructure of martensite and retained austenite can be obtained by heat treatment of spring steel by $\mathrm{Q} \& \mathrm{P}$ process, and it has the advantages of both high strength and high plasticity in performance[1-4].

Although the $\mathrm{Si}$ and $\mathrm{Al}$ elements in the spring steel can inhibit the precipitation of cementite in the $\mathrm{Q} \& \mathrm{P}$ process,E.P.Da Siva, D.De knijf, D.V.Edmods and Moor[5-6] all indicate that carbides precipitation in the partition period cannot be completely suppressed even in low carbon steels with relatively high $\mathrm{Si}$ and $\mathrm{Al}$ content, especially transition carbides[7-8]. While precipitation of carbides and the diffusion of carbon in martensite into austenite are a competition mechanism.Carbides precipitation not only lead to the less content of retained austenite at room temperature, but also contribute to poor carbon in martensite, which can reduce comprehensive mechanical properties.As the second phase particle precipitation, the size of carbides will affect the mechanical properties of steel[9-10].The large size carbide particles formed in partition time are easy to cause stress concentration, reduce the plasticity and toughness, and it will result in serious brittle fracture.So,in addition to martensite,precipitation of carbides is also an important factor determining the mechanical properties of spring steel treated by Q\&P process[11-12].

There were no systemic study of precipitation of spring steel in the partition of carbides and its effects on the mechanical properties in the domestic and foreign literatures.The purpose of the present work was to explore the influence ofcarbides on mechanical properties by the statistics of carbides precipitation types, quantity and size distribution of spring steel after different Q\&P processes, and calculate the contribution to strength.It is determined that In addition to the changes in mechanical properties caused by different tissue structures, the contribution of carbides precipitation strengthening is confirmed,which can provide guidance for optimizing mechanical properties.

\section{MATERIALS AND EXPERIMENTS PROCEDURES}

The material was cut into $\varphi 4 \mathrm{~mm} \times 10 \mathrm{~mm}$ small cylinder and then the thermal expansion test was conducted using the DIL805 A / D. The heat treatment process was shown in Table 1 . Ac3 point of the 60Si2CrVA spring steel is $790{ }^{\circ} \mathrm{C}$, specimens were com-pletely austenitized at $860{ }^{\circ} \mathrm{C}$ for $15 \mathrm{~min}$ by dilatometry, and cooled to $200{ }^{\circ} \mathrm{C}$ $\left(\mathrm{Ms}=252{ }^{\circ} \mathrm{C}\right.$ ), then partitioning at $360{ }^{\circ} \mathrm{C}$ of different partition time(30 s,600s,1200s,3600s), finally qenching to room temperature.

The above-mentioned specimens processed by Q \& $\mathrm{P}$ were mechanically ground and polished,then corroded with 4 voL\% nitric acid alcohol solution, and the specimens were analyzed by KYKY-2800B scanning electron microscopy for microstructure and carbides observation.Each sample was selected 100 carbide particles, and carbides size distribution was counted by ImageJ software.In this paper, the method of counting the size of the carbides was the maximum length of the particles and the vertical dimension of the average as the particle diameter[13], and the specimens processed by Q\&P with partition time of 1200 s were extracted by electrolysis with reference to the extraction standard of carbides. The electrolyte container was made of stainless steel, which was directly used as the cathode; the electrolyte was $8 \% \mathrm{HCl}$ and $5 \%$ citric acid, and the solution $\mathrm{pH}$ was about 4 , the curret density was $0.05 \mathrm{~A} / \mathrm{cm} 2$, the extraction time was $10 \mathrm{~h}$, and The temperature was controlled at $5{ }^{\circ} \mathrm{C}$. When the extraction was completed, the 
carbides powders were washed with alcohol by ultrasonic vibration, and then the carbide powders were dried.The morphology of carbide particles was observed by KYKY-2800B scanning electron microscopy, and chemical element composition was determined by EDS.

At last $150 \mathrm{~mm}$ tensile specimens cut by the wire cutting machine was conducted heat treatment, and then finish machining according to the standard tensile specimen drawings. The tensile specimen length was $\mathrm{L}=150 \mathrm{~mm}, \mathrm{~d}=$ $5 \mathrm{~mm}$, and the tensile strength, yield strength, elongation and shrinkage were obtained by the MTS electrohydraulic servo universal testing machine,and tension test was conducted according to the national standard GB228-2002, at the beginning of the tensile rate was $1 \mathrm{~mm} / \mathrm{min}$, and removed the extensormeter, stretching rate was $2 \mathrm{~mm} / \mathrm{min}$.

\section{RESULTS AND DISCUSSIONS}

\section{A. Effects of the partition time on the size distribution of carbides and microstructure}

SEM microstructure of the different partition time as shown Figure 1 .Some larger blocky M/A islands are still visible, and the microstructure of acicular martensite appears, when the partition is set to a temperature of $360^{\circ} \mathrm{C}$ and partition time of 30s. The microstructure of martensite + bainite + retained austenite appears when the partition time is up to $600 \mathrm{~s}$. With the extension of the partition time, the characteristics of martensite almost disappeared and only some blocky M/A islands existed, but the size of the bright white and dark grey carbides became large.

TABLE I. PARAMETERS OF HEAT TREATMENT

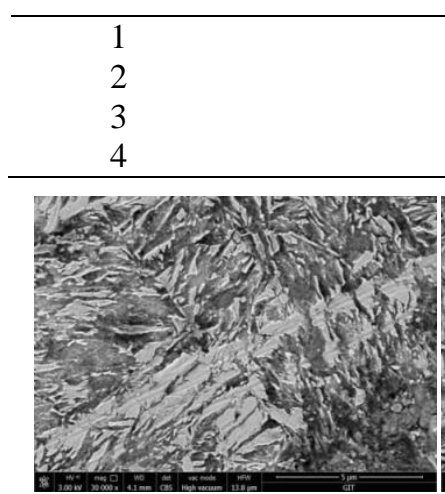

(a)

$860^{\circ} \mathrm{C} \times 15 \mathrm{~min} \rightarrow 200^{\circ} \mathrm{C} \times 20 \mathrm{~s} \rightarrow 360^{\circ} \mathrm{C} \times 30 \mathrm{~s} \rightarrow$ cooled to room temperature $860^{\circ} \mathrm{C} \times 15 \mathrm{~min} \rightarrow 200^{\circ} \mathrm{C} \times 20 \mathrm{~s} \rightarrow 360^{\circ} \mathrm{C} \times 600 \mathrm{~s} \rightarrow$ cooled to room temperature $860^{\circ} \mathrm{C} \times 15 \mathrm{~min} \rightarrow 200^{\circ} \mathrm{C} \times 20 \mathrm{~s} \rightarrow 360^{\circ} \mathrm{C} \times 1200 \mathrm{~s} \rightarrow$ cooled to room temperature $860^{\circ} \mathrm{C} \times 15 \mathrm{~min} \rightarrow 200^{\circ} \mathrm{C} \times 20 \mathrm{~s} \rightarrow 360^{\circ} \mathrm{C} \times 3600 \mathrm{~s} \rightarrow$ cooled to room temperature

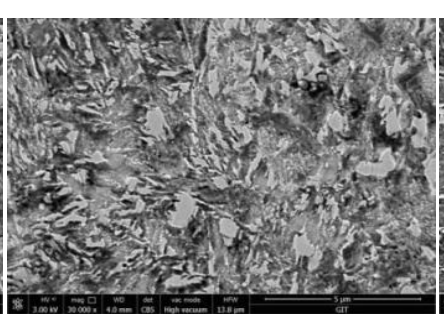

(b)

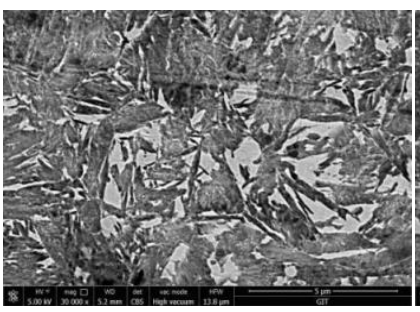

(c)

(a) $200^{\circ} \mathrm{C}-360^{\circ} \mathrm{C}-30 \mathrm{~s}$, (a) $200{ }^{\circ} \mathrm{C}-360^{\circ} \mathrm{C}-600 \mathrm{~s}(\mathrm{c}) 200^{\circ} \mathrm{C}-360^{\circ} \mathrm{C}-1200 \mathrm{~s}$, (d) $200{ }^{\circ} \mathrm{C}-360^{\circ} \mathrm{C}-3600 \mathrm{~s}$

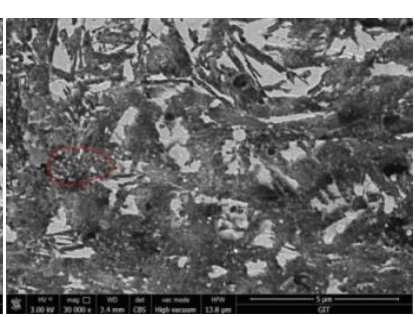

(d)

Figure 1. SEM of different partition time.
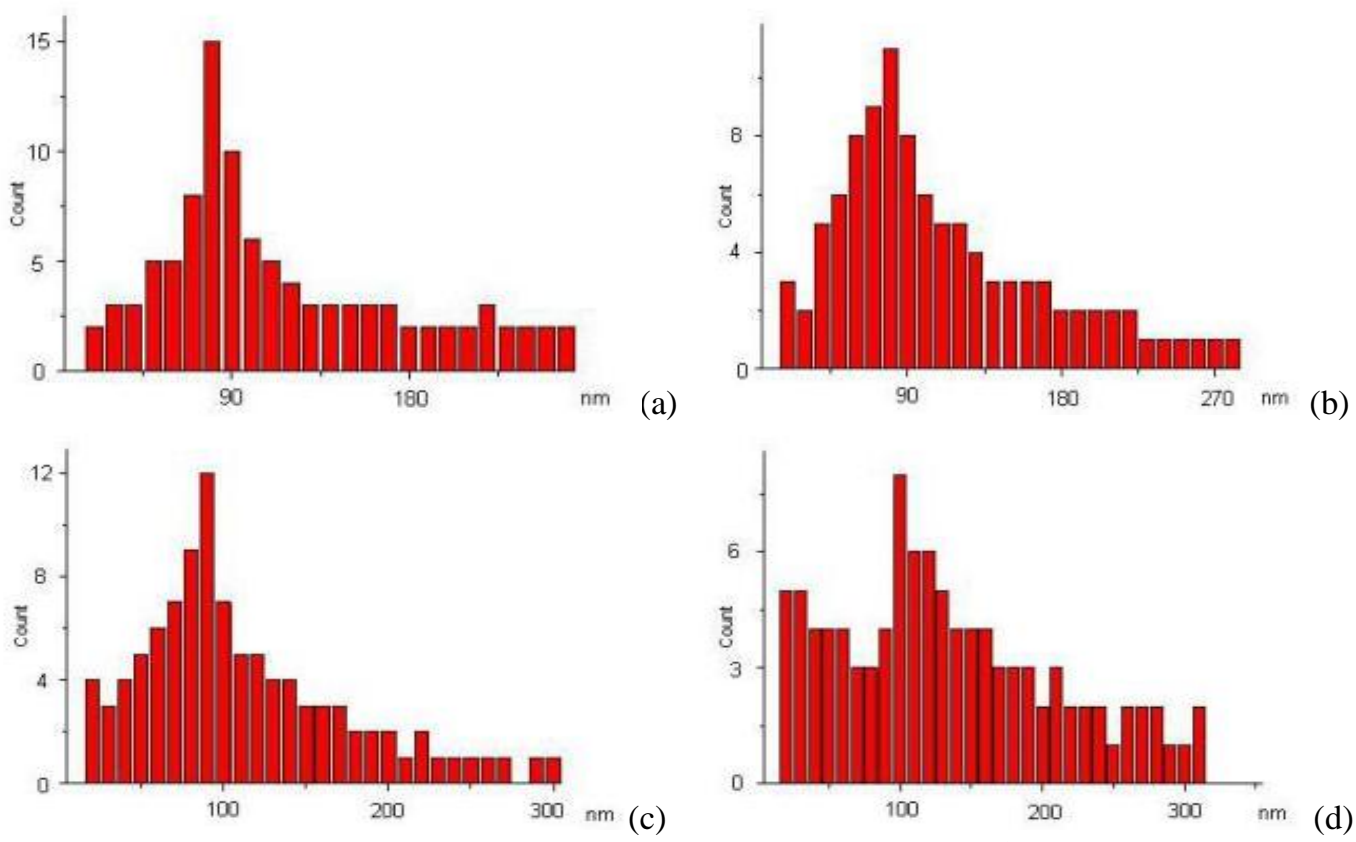

(a) $200^{\circ} \mathrm{C}-360^{\circ} \mathrm{C}-30 \mathrm{~s}$, (a) $200^{\circ} \mathrm{C}-360^{\circ} \mathrm{C}-600 \mathrm{~s}$ (c) $200^{\circ} \mathrm{C}-360^{\circ} \mathrm{C}-1200$ s, (d) $200^{\circ} \mathrm{C}-360^{\circ} \mathrm{C}-3600 \mathrm{~s}$

Figure 2. Size distribution chart of carbides particles. 
The size distribution of carbide particles with different partition times is shown in Fig.2.The distribution frequency is the highest, when the size of the particles is about $70 \mathrm{~nm}$. the distribution frequency is the highest the maximum size of $250 \mathrm{~nm}$ of the partition time at $30 \mathrm{~s}$. When the partition time is extended to $3600 \mathrm{~s}$, the highest frequency particle size of carbides is about $100 \mathrm{~nm}$, and the biggest size is about 300 $\mathrm{nm}$. The more fully atomic diffusion, with the longer time, the more opportunities to grow were provided for carbides, and they could grow up easily. As is shown in distribution charts, although the particles were growing up with the extension of partition time, there was an increasing tendency of small particles of carbides in $10-20 \mathrm{~nm}$, the phenomenon of fine carbide clusters could be observed by part of the red circle of Fig1 (d), the reason why led to this phenomenon could be when the temperature reaches a certain temperature and the partition time is long enough, large carbides are decomposed into fine carbides.

\section{B. Effect of carbide size distribution on mechanical properties in different $Q \& P$ processes}

According to the statistical graph of particle size distribution above, the size of precipitated carbides is larger than $10 \mathrm{~nm}$, Precipitation strengthening effect produced mainly by bypass mechanism. The method of subsection calculation and summation is adopted in this paper to accurately calculate the precipitates contribution to strength. According to McCall-Boyd [14] and Ashby-Orowan [15]correction model. The volume fraction of carbides preci-pitated and the formula of precipitation hardening in the process of partitioning of $60 \mathrm{Si} 2 \mathrm{CrVA}$ treated by $\mathrm{Q} \& \mathrm{P}$ process can be written as follows:

$$
\begin{gathered}
f_{i}=\left(\frac{1.4 \pi}{6}\right) \cdot\left(\frac{N_{i} D_{i}^{2}}{A}\right) \\
\sigma_{s}=\sum_{i=1}^{n} \sigma_{i}=\sum_{i}^{n}\left\lfloor\frac{10 \mu b}{5.72 \pi^{3 / 2} r_{i}} \cdot f_{i}^{\frac{1}{2}} \ln \left(\frac{r_{i}}{b}\right)\right\rfloor
\end{gathered}
$$

$\mathrm{A}$ is the area of the photograph, $\mathrm{Ni}$ for a range of carbon number, Di is the average diameter of carbides in an interval, $u m$; $r i$ is the average radius of a range of carbides, um; fi is the total volume of a range of carbides precipitation; $\mu$ is shear coefficient, for steel, the value is $80.26 \times 103 \mathrm{MPa}$; $b$ is burgers vector, the value is $2.48 \times 10-4 \mathrm{um}$. The volume fraction of the carbides precipitation and precipitation strengthening can be obtained in this way: starting from 10 $\mathrm{nm}$, the number of precipitates in each interval was calculated by using the span of $10 \mathrm{~nm}$ as an interval, and the corresponding equivalent mean radius, volume fraction and precipitation enhancement amount were calculated. Finally, all intervals were accumulated. The total volume fraction and the total precipitation strengthening amount are the carbides volume fraction and precipitation strengthening amount of $60 \mathrm{Si} 2 \mathrm{CrVA}$ precipitated in the process of $\mathrm{Q} \& \mathrm{P}$ treatment.

As is shown in table 3 , the average size and volume fraction of carbides increase with the extension of partition time, because the diffusion and migration of carbides have enough time, which makes the carbides gather, nucleated and grow gradually. The contribution of carbides to the strength calculated by formula (1) and (2) of each partition time decreases with the prolongation of the partition time. From table 2, it can be observed that the strength of materials increases first and then decreases with the increase of partition time, which proves the change of tissue structure in the partitioning process, and it has greater influence on strength. When the partition time is extended from 30 s to $600 \mathrm{~s}$, the strength decreases. The reason is the carbon in martensite diffuses to the retained austenite and make it rich in carbon, the increase of retained austenite from table 2 can reflect this phenomenon. When the partition time is extended to $1200 \mathrm{~s}$, the strength is increased instead, which is due to the transformation of reduction leaded by decomposition of (1)martensite [16-17].

TABLE II. MECHANICAL PROPERTIES OF DIFFERENT PARTITION TIME

\begin{tabular}{|c|c|c|c|c|}
\hline & $\mathrm{Ar} / \%$ & $\sigma b / M p a$ & $\sigma_{0.2} / M p a$ & $H R C$ \\
\hline $30 \mathrm{~s}$ & 14.26 & 1892 & 1715 & 49.27 \\
\hline $600 \mathrm{~s}$ & 15.15 & 1753 & 1627 & 44.61 \\
\hline $1200 \mathrm{~s}$ & 11.86 & 1823 & 1684 & 40.26 \\
\hline $3600 \mathrm{~s}$ & 11.51 & 1789 & 1643 & 37.58 \\
\hline
\end{tabular}

TABLE III. CONTRIBUTION OF CARBIDES TO STRENGTH OF DIFFERENT PARTITION TIME

\begin{tabular}{|c|c|c|c|c|}
\hline & $\begin{array}{c}\text { Average } \\
\text { size/nm }\end{array}$ & $\begin{array}{c}\text { Volume fraction } \\
/ \%\end{array}$ & Contribution to strength/MPa & The proportion of the total strength /\% \\
\hline $30 \mathrm{~s}$ & 72.16 & 1.83 & 307.95 & 17.96 \\
\hline $600 \mathrm{~s}$ & 84.25 & 2.54 & 286.13 & 16.52 \\
\hline $1200 \mathrm{~s}$ & 99.28 & 2.86 & 256.21 & 15.20 \\
\hline $3600 \mathrm{~s}$ & 113.4 & 3.43 & 248.87 & 15.09 \\
\hline
\end{tabular}




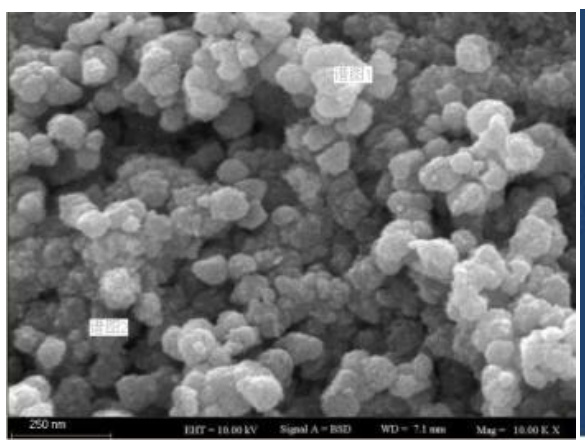

(a)

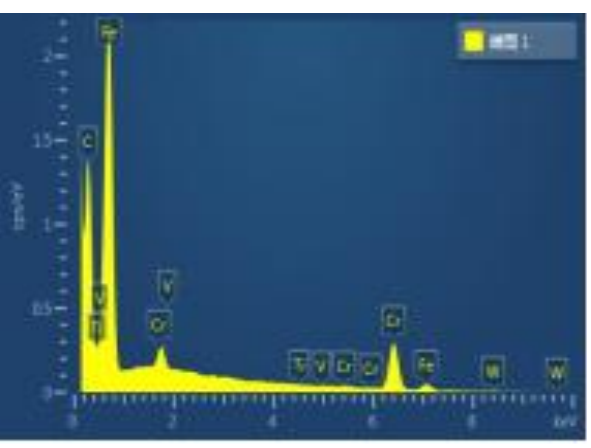

(b)

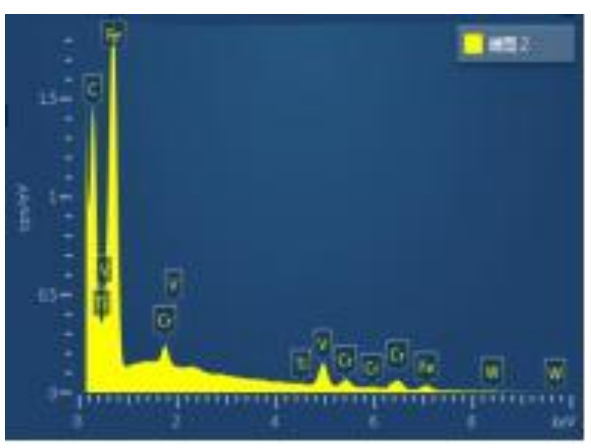

(c)

(a)SEM of carbides by electrolytic extraction; (b)EDS1(c)EDS2

Figure 3. Precipitation of carbides during the partitioning process

TABLE IV. CONTRIBUTION OF DIFFERENT KINDS OF CARBIDES TO STRENGTH DURING THE PARTITIONING PROCESS

\begin{tabular}{|c|c|c|}
\hline & Carbides rich in $\mathrm{V}(\leq 80 \mathrm{~nm})$ & Farbides rich in $\mathrm{Cr}(>80 \mathrm{~nm})$ \\
\hline contribution value/MPa & 183.13 & 69.96 \\
\hline Contribution ratio $/ \%$ & 72.36 & 27.64 \\
\hline
\end{tabular}

C. Types of carbides and contribution to yield strength of different types of carbides

The samples treated by Q\&P $\left(\mathrm{QT}=200^{\circ} \mathrm{C}, \mathrm{PT}=360^{\circ} \mathrm{C}, \mathrm{Pt}=1200 \mathrm{~s}\right)$, process were extracted by electrolysis to obtain carbide particles. The carbide particles obtained were observed by scanning electron microscope and morphology of carbides were shown in Figure3(a), and Figure(b) was energy spectra of bright white carbide particles in Figure(a), the main alloying elements of the carbides are $\mathrm{C}$ and $\mathrm{Cr}$, the mass fraction were $29 \%$ and $18 \%$ respectively, and it was determined that the carbides were rich in $\mathrm{Cr}$. Figure(c) was energy spectra of gray black carbide particles in Figure(a), the main alloying elements of the carbides are $\mathrm{C}$ and $\mathrm{V}$, the mass fraction were $32 \%$ and $16 \%$ respectively, so It could be concluded that this kind of carbides were rich in $\mathrm{V}$.

The size statistics of two kinds of carbides were calculated respectively, and it is concluded that the size distribution of carbides of $\mathrm{V}$ was less than or equal to $80 \mathrm{~nm}$, while, the range of size distribution of $\mathrm{Cr}$ carbides is greater than $80 \mathrm{~nm}$. The content of $\mathrm{Cr}$ in $60 \mathrm{Si} 2 \mathrm{CrVA}$ is higher, so its carbides tend to aggregate and grow; carbides rich in $\mathrm{V}$ and carbides rich in $\mathrm{Cr}$ have different nucleation sites, the former is mainly formed in the original austenite crystal[18-20], while the latter is formed at grain boundaries and martensite lath boundaries. The precipitation diffusion rate is higher in the original austenite. Therefore, carbides rich in $\mathrm{V}$ distribute dispersedly and have smaller particles [21]. It is calculated according to formula (1) and (2) that the contribution of carbides rich in $\mathrm{V}$ to strength is $183.13 \mathrm{MPa}$, and the contribution of $\mathrm{Cr}$ to the strength is $69.963 \mathrm{MPa}$.It can be found that the contribution of $\mathrm{Cr}$ carbides to the strength is relatively weak, while the carbides of $\mathrm{V}$ play a dominant role in precipitation strengthening.

\section{CONCLUSIONS}

Precipitation behavior and strengthening of carbides is studied by electrolytic extraction technology, SEM and EDS during the application of the Q\&P process with different partition time to $60 \mathrm{Si} 2 \mathrm{CrVA}$ spring steel and precipitation strength is calculated. The main conclusions are:

(1)The size and volume fraction of carbides increase continuously with the extension of partition time, and the maximum size is about $300 \mathrm{~nm}$, while the contribution of carbides to yield strength decreases gradually.

(2)After SEM observation of the carbides obtained by electrolytic extraction, it is found that the bright white precipitate is the carbides rich in $\mathrm{Cr}$, and the dark grey precipitate is the carbides rich in $\mathrm{V}$, both of them are irregular spheres. The former size is larger than $80 \mathrm{~nm}$, and the latter is below $80 \mathrm{~nm}$.

(3)The calculation of precipitation strengthening of different types of carbides during the partition process of $60 \mathrm{Si} 2 \mathrm{CrVA}$ spring steel is described that the contribution of carbides rich in $\mathrm{Cr}$ to precipitation strengthening is weak, carbides rich in $\mathrm{V}$ play the key role in precipitation strengthening, and their proportion of total precipitation strengthening is $72.36 \%$.

\section{ACKNOWLEDGMENT}

This work is supported by the National Natural Science Foundation of China (Grant Nos. 51571066and 51461008) and Innovative Talents Project of Guizhou Province (Grant No.20165654).

\section{REFERENCES}

[1] Speer J.G.,Matlock D.K.,Carbon Partitio-ning into Austenite after Martensite Tran-sformation[J], Acta Mater, 51, 2611.-2622, (2003).

[2] Gerdmamm F.L.H.,Speer J.G.,Matlock D.K.Microstructure and Hardness of Steel Grade 9260 Heat-treated by the Quenching and Partitioning(Q\&P)Process[J], MS\&T 2004 Conference Proceeding,439-449.

[3] Donghwi Kim,Seok-Jae Lee,Microstructure of Low C Steel 
Isothermally Transformed in The Ms to Mf Temperature Rang[J],Met and Trans A,volum43A,4967-4983,(2012).

[4] S.M.C. Van Boheman,J. Sietsma,The Kin-etics of Bainite and Martensite Formati-on in Steel during Cooling[J],Materials Science and Engineering A,527,6672-3376,(2010).

[5] Silva E P D, Knijf D D, Xu W, et al. Isothermal transformations in advanced high strength steels below martensite start temperature[J]. Materials Science \& Technology, 2015, 31(7):808-816.

[6] Moor E De Lacroixs S C larke A J eta-l. Effect of retained austenite stablilized via quenching and partioning on strain harding of martensitic steels[J].Metallugic-al and Mateials Transactions A.2008.39;2586-2595.

[7] M.J. Santofimia, L. Zhao, J. Sietsma, Metall. Mater. Trans. A 42A (2011) 3620.

[8] S.M.C. Van Boheman,M.J. Santofimia,J. Sietsma.Experimental Evidence for Bainite Formation below $\mathrm{Ms}$ in Fe-0.66C,Scripta Materialia ,58,488-491,(2008).

[9] Kondrat'Ev S Y, Kraposhin V S, Anast-asiadi G P, et al. Experimental observa-ntion and crystallographic description of $\mathrm{M} 7 \mathrm{C} 3$, carbide transformation in Fe-Cr-Ni-C HP type alloy[J]. Acta Materialia, 2015, 100:275-281.].

[10] Sajjadi S A, Zebarjad S M. Isothermal transformation of austenite to bainite in high carbon steels[J], Journal of Materials Processing Technology, 189(1-3),107-113,(2007).

[11] Navarro-López A, Sietsma J. Effect of P-rior Athermal Martensite on the Isother-mal Transformation Kinetics Below Ms in a Low-C High-Si Steel[J],Metallurgica-1 and Materials Transactions A, 47(3),1028-1039,(2016).

[12] Park H S, Seol J B, Lim N S,Study of the decomposition behavior of retained austenite and the partitioning of alloying elements during tempering in CMnSiAl TRIP steels[J],Materials \& Design, 82(2),173-180,(2015).
[13] Prat O, Garcia J, Rojas D, et al. Investigations on coarsening of MX and $\mathrm{M} 23 \mathrm{C} 6$, precipitates in $12 \% \mathrm{Cr}$ creep resistant steels assisted by computational thermodynamics[J]. Materials Science \& Engineering A, 2010, 527(21):5976-5983.

[14] G.E.Pellissier. Stereology and quantitative metallography [M]. Publishing House of mechanical industry, 1980.

[15] Kneissl A C, Garcia C I, Deardo A J. Charecterization of precipitates in HSLA steel. HSLA Steels: Processing, Properties and Applications. Edited by Geoffrey Tither and Zhang Shouhua. The Minerals, Metals and Materials Society, 1992: 99-1 02.

[16] Liu J, Luo C P. Precipitation behavior of the lower bainitic carbide in a medium-carbon steel containing $\mathrm{Si}, \mathrm{Mn}$ and $\mathrm{Mo}[\mathrm{J}]$. Materials Science \& Engineering A, 2006, 438(24):153-157.

[17] Seo E J, Cho L, Cooman B C D. Kinetics of the partitioning of carbon and substitutional alloying elements during quenching and partitioning (Q\&P) processing of medium Mn steel[J]. Acta Materialia, 2016, 107:354-365.

[18] Voicu R, Andrieu E, Poquillon D, et al. Microstructure evolution of $\mathrm{HP} 40-\mathrm{Nb}$ alloys during aging under air at $1000{ }^{\circ} \mathrm{C}[\mathrm{J}]$. Materials Characterization, 2009, 60(9):1020-1027.

[19] Kondrat'Ev S Y, Kraposhin V S, Anast-asiadi G P, et al. Experimental observa-ntion and crystallographic description of M 7 C 3, carbide transformation in $\mathrm{Fe}-\mathrm{Cr}-\mathrm{Ni}-\mathrm{C}$ HP type alloy[J]. Acta Ma-terialia, 2015, 100:275-281.].

[20] Prat O, Garcia J, Rojas D, et al. Investigations on coarsening of MX and M 23 C 6, precipitates in 12\% Cr creep resistant steels assisted by computational thermodynamics[J]. Materials Science \& Engineering A, 2010, 527(21-22):5976-5983.

[21] Kaneko K, Matsumura S, Sadakata A, e-t al. Characterization of carbides at dif-ferent boundaries of $9 \mathrm{Cr}$-steel[J]. Materi-als Science \& Engineering A, 2004, 374(1):82-89. 